\title{
Step Changes and Deactivation Behavior in the Continuous Decarboxylation of Stearic Acid
}

Madsen, Anders Theilgaard; Rozmysowicz, Bartosz; Simakova, Irina L.; Kilpio, Teuvo; Leino, AnneRiikka; Kordas, Krisztian; Eranen, Kari; Maki-Arvela, Paivi; Murzin, Dmitry Yu.

Published in:

Industrial \& Engineering Chemistry Research

Link to article, DOI:

10.1021/ie201273n

Publication date:

2011

Document Version

Publisher's PDF, also known as Version of record

Link back to DTU Orbit

Citation (APA):

Madsen, A. T., Rozmysowicz, B., Simakova, I. L., Kilpio, T., Leino, A-R., Kordas, K., Eranen, K., Maki-Arvela, P., \& Murzin, D. Y. (2011). Step Changes and Deactivation Behavior in the Continuous Decarboxylation of Stearic Acid. Industrial \& Engineering Chemistry Research, 50(19), 11049-11058. https://doi.org/10.1021/ie201273n

\section{General rights}

Copyright and moral rights for the publications made accessible in the public portal are retained by the authors and/or other copyright owners and it is a condition of accessing publications that users recognise and abide by the legal requirements associated with these rights.

- Users may download and print one copy of any publication from the public portal for the purpose of private study or research.

- You may not further distribute the material or use it for any profit-making activity or commercial gain

- You may freely distribute the URL identifying the publication in the public portal 


\title{
Step Changes and Deactivation Behavior in the Continuous Decarboxylation of Stearic Acid
}

\author{
Anders Theilgaard Madsen, ${ }^{+, \neq}$Bartosz Rozmysłowicz, ${ }^{\ddagger}$ Irina L. Simakova, ${ }^{\neq, \S}$ Teuvo Kilpiö, \\ Anne-Riikka Leino," Krisztián Kordás," Kari Eränen, ${ }^{\neq}$Päivi Mäki-Arvela, ${ }^{\neq}$and Dmitry Yu. Murzin ${ }^{*, \neq}$ \\ ${ }^{\dagger}$ Centre for Catalysis and Sustainable Chemistry, Technical University of Denmark, DK-2800 Kgs. Lyngby, Denmark \\ ${ }^{\ddagger}$ Process Chemistry Center, Åbo Akademi University, Biskopsgatan 8, FI-20500 Turku/Åbo, Finland \\ ${ }^{\S}$ Boreskov Institute of Catalysis, Prospekt akademika Lavrentieva 5, Novosibirsk, Russia 630090 \\ "Laboratory of Microelectronics and Materials Physics, University of Oulu, PL 4500, 90014 Oulu, Finland
}

ABSTRACT: Deoxygenation of dilute and concentrated stearic acid over 2\% $\mathrm{Pd} / \mathrm{C}$ beads was performed in a continuous reactor at $300{ }^{\circ} \mathrm{C}$ and 20 bar pressure of $\mathrm{Ar}$ or $5 \% \mathrm{H}_{2} / \mathrm{Ar}$. Stable operation was obtained in $5 \% \mathrm{H}_{2}$ atmosphere, with $95 \%$ conversion of 10 mol $\%$ dilute stearic acid in dodecane and $12 \%$ conversion of pure stearic acid. Deactivation took place in $\mathrm{H}_{2}$-deficient gas atmosphere, probably as a result of the formation of unsaturated products and coking in the pore system. Transient experiments with step changes were performed: $1 \mathrm{~h}$ was required for the step change to be visible in liquid sampling, whereas steady states were achieved after a total of 2.5-3 h. Postreaction analysis of the spent catalyst revealed that a deactivation profile was formed downward over the catalyst bed.

\section{INTRODUCTION}

The diminishing availability of cheap fossil fuels and the impact of fossil fuels on the global environment have led to a struggle toward higher fuel efficiency and the development of alternative fuels for road vehicles. The European Union (EU) mandated that at least $5.75 \%$ of the energy content in diesel and petrol should be based on biofuels by the end of 2010, rising to $10 \%$ in 2020. ${ }^{1}$ Lately, in its 2010 report, the International Energy Agency (IEA) described the urgent need for a swift transition toward more sustainable and environmentally sound energy and fuel production. ${ }^{2}$

Fats and oils are generally the types of biomass resources that, from a chemical point of view, most closely resemble diesel oil and are easiest to upgrade into a diesel fuel. ${ }^{3,4}$ Diesel fuel can be made from fats and oils by (trans-)esterification with methanol to form fatty acid methyl esters (FAMEs), which have been investigated extensively. Another approach could be through the deoxygenation of fats and oils potentially using hydrogen (socalled hydrodeoxygenation, or HDO) to form straight-chain alkanes, which is advantageous under some conditions. ${ }^{5}$

The HDO process was first introduced on an industrial scale in 2007 by Neste Oil in Porvoo, Finland, based primarily on palm oil, ${ }^{6,7}$ and other companies are following the same route. To date, however, reports on understanding deoxygenation processes have not been extensive. Generally, three types of catalysts have been applied for the deoxygenation of fatty feedstocks, namely, supported sulfided metals catalysts, supported metallic catalysts, and porous acidic or basic catalysts. Deoxygenation has been described to occur by three different routes: decarboxylation, decarbonylation, or full reduction with hydrogen (reactions $1-3$ ), in all cases yielding $n$-alkanes upon saturation with hydrogen.

$$
\begin{aligned}
& \mathrm{C}_{17} \mathrm{H}_{35}(\mathrm{CO}) \mathrm{OH} \rightarrow \mathrm{CO}_{2}+\mathrm{H}_{3} \mathrm{C}-\mathrm{C}_{16} \mathrm{H}_{33} \\
& \mathrm{C}_{17} \mathrm{H}_{35}(\mathrm{CO}) \mathrm{OH} \rightarrow \mathrm{CO}+\mathrm{H}_{2} \mathrm{O}+\mathrm{H}_{2} \mathrm{C}=\mathrm{C}_{16} \mathrm{H}_{32}
\end{aligned}
$$

$\mathrm{C}_{17} \mathrm{H}_{35}(\mathrm{CO}) \mathrm{OH} \stackrel{+3 \mathrm{H}_{2}}{\longrightarrow} 2 \mathrm{H}_{2} \mathrm{O}+\mathrm{C}_{2} \mathrm{H}_{5}-\mathrm{C}_{16} \mathrm{H}_{33}$

In addition to direct decarboxylation, generation of linear hydrocarbons from free fatty acids could also proceed through formation of formic acid and alkenes and their subsequent reactions, as elaborated further in Results and Discussion section.

The primary reaction route and the side reactions taking place are strongly dependent on the catalyst used - especially reactions of hydrogen and product gases may interfere and prompt the water-gas shift (WGS) or methanation (reactions 4-6).

$$
\begin{aligned}
& \mathrm{H}_{2} \mathrm{O}+\mathrm{CO} \rightleftharpoons \mathrm{CO}_{2}+\mathrm{H}_{2} \\
& 3 \mathrm{H}_{2}+\mathrm{CO} \rightarrow \mathrm{CH}_{4}+\mathrm{H}_{2} \mathrm{O} \\
& 4 \mathrm{H}_{2}+\mathrm{CO}_{2} \rightarrow \mathrm{CH}_{4}+2 \mathrm{H}_{2} \mathrm{O}
\end{aligned}
$$

A number of reports have appeared on catalytic crackingtype reactions of various vegetable oils without added hydrogen. These are usually performed at $400-500{ }^{\circ} \mathrm{C}$ without $\mathrm{H}_{2}$ in the reaction medium. ${ }^{8-13}$ FAMEs have also been used as feedstocks. ${ }^{14,15}$ Porous Brønsted acidic materials tested include H-MCM-41 and the zeolites H-ZSM-5 and H-Y. ${ }^{8-11,15}$ Porous basic materials tested include zeolite $(\mathrm{Cs}, \mathrm{Na})-\mathrm{X}$, hydrotalcites, and porous $\mathrm{SnO}-\mathrm{ZnO}-\mathrm{Al}_{2} \mathrm{O}_{3} \cdot{ }^{12-14} \mathrm{Generally,}$ the procedures result in a mixture of hydrocarbons due to cracking reactions, as well as light gases and coke; petroleum can often be the product with the highest yield. Saponification of the resulting free fatty acids can also occur over some basic catalysts such as $\mathrm{MgO}^{12,14}$

Received: June 15, 2011

Accepted: September 2, 2011

Revised: $\quad$ August 11, 2011

Published: September 02, 2011 
Sulfided $\mathrm{NiMo} / \mathrm{Al}_{2} \mathrm{O}_{3}$ and $\mathrm{CoMo} / \mathrm{Al}_{2} \mathrm{O}_{3}$ at $250{ }^{\circ} \mathrm{C}$ under 15 or 75 bar of $\mathrm{H}_{2}$ and various sulfidation conditions have been studied as HDO catalysts. The conversion of heptanoic alcohol, acid, and esters and the ratio between $\mathrm{C}_{6}$ and $\mathrm{C}_{7}$ hydrocarbons were found to vary depending on the catalyst type and added sulfur compounds in the feed. Unsulfided $\mathrm{NiMo} / \mathrm{Al}_{2} \mathrm{O}_{3}$ and $\mathrm{CoMo} / \mathrm{Al}_{2} \mathrm{O}_{3}$ catalysts were neither very active nor selective toward linear hydrocarbons; however, the sulfided catalysts had high activities and yielded higher ratios of $\mathrm{C}_{6} / \mathrm{C}_{7}$ hydrocarbon products. ${ }^{16,17}$ The conversion of rapeseed oil over various sulfided $\mathrm{NiMo} / \mathrm{Al}_{2} \mathrm{O}_{3}$ catalysts has also been investigated at temperatures in the range of $260-360{ }^{\circ} \mathrm{C}$ and pressures of $70-150$ bar $\mathrm{H}_{2}$. The effects of pressure, temperature, sulfidation conditions, and $\mathrm{Ni}$ and $\mathrm{Mo}$ composition of the catalyst were studied. ${ }^{18-20}$ Co hydrocracking of 5\% rapeseed oil in vacuum gas oil over sulfided $\mathrm{NiMo} / \mathrm{Al}_{2} \mathrm{O}_{3}$ at higher temperatures $\left(400-420{ }^{\circ} \mathrm{C}\right)$ was also investigated. ${ }^{21}$ Supporting sulfided CoMo on inorganic mesoporous materials showed that organized mesoporous alumina provided better performance than the reference industrial $\gamma$-alumina as a support, which, in turn, exhibited a better performance than MCM-41 mesoporous alumina-silicates. Incorporating more $\mathrm{Al}$ into the $\mathrm{Si}$ framework of MCM-41 increased the hydrocarbon yield. ${ }^{2,23}$ The $\mathrm{HDO}$ of sunflower and palm oil was also studied over sulfided $\mathrm{NiMo} / \mathrm{Al}_{2} \mathrm{O}_{3}$ both neat and in a mixture with vacuum gas oil. $^{24,25}$ Decarboxylation is generally favored by higher temperatures and low pressures of $\mathrm{H}_{2}$ over sulfided catalysts.

Deoxygenation of triglycerides with supported transition metals has been scarcely studied: ${ }^{26-31}$ Typically, high-surfacearea oxide or carbon materials are used for supporting $\mathrm{Pd}$ or $\mathrm{Pt}$ metals, ${ }^{26,27}$ and isomerization can be performed simultaneously by using strongly acidic porous materials as the support or cosupport. $^{28-30}$ Also, FAME deoxygenation has successfully been performed over Pt-based catalyst at $300-350{ }^{\circ} \mathrm{C}$ in 6.9 bar of $\mathrm{H}_{2}$ or He. ${ }^{31}$

Several waste feedstocks such as abattoir waste, used cooking oils, and greases contain considerable amounts of free fatty acids (FFAs). FFAs are also intermediates in the deoxygenation of corresponding esters. $^{27,32}$ The study of FFAs can therefore be considered crucial for understanding deoxygenation. Palladium and platinum metals have previously been found to be the most selective and active catalysts for the decarboxylation of FFAs. ${ }^{33}$ Various decarboxylation parameters have previously been investigated in semibatch mode (stirred autoclave with liquid reactants and continuous renewal of only the gas phase), primarily with stearic acid as a feedstock over commercial Pd catalysts, Pd on SBA-15 or Pd on Sibunit carbon (a mesoporous and temperature-stable carbon composite). ${ }^{34-36}$ It was found that the deoxygenation rate was independent of the fatty acid chain length in the range of $\mathrm{C}_{18}-\mathrm{C}_{23}{ }^{37}$ Tall oil fatty acids (TOFAs) are byproducts from the Kraft process (for making cellulose fibers from wood), and their deoxygenation was investigated over $\mathrm{Pd} /$ sibunit. $^{38}$ Deactivation was especially pronounced with unsaturated fatty acids; therefore, it is suspected to occur through cyclization from $\mathrm{C}=\mathrm{C}$ double bonds in the feedstock, followed by dehydrogenation over $\mathrm{Pd}$ catalyst, thus forming $\mathrm{C}_{17}$ aromatic hydrocarbons. ${ }^{35,38,39}$

Continuous decarboxylation of stearic acid, a typical fatty acid found especially in saturated fats was recently demonstrated in continuous mode over $\mathrm{Pd} / \mathrm{C}$ catalysts at $300-360{ }^{\circ} \mathrm{C} .{ }^{35,40}$ Continuous reactors are more industrially interesting than batch or semibatch reactors, and it is necessary to obtain information on long-term performance and transients during continuous decarboxylation to describe the catalyst involved. In this work, the continuous decarboxylation of stearic acid at $300{ }^{\circ} \mathrm{C}$ was investigated with the aim of describing step changes during startup and shutdown, steady-state conversion, and deactivation phenomena.

\section{EXPERIMENTAL SECTION}

2.1. Chemicals. Stearic acid ( $>99 \%$ purity) was supplied by Sigma-Aldrich. N,O-bis(trimethylsilyl)trifluoroacetamide (BSTFA, $>99 \%$ purity) as a silylation agent was provided by Acros Organics. $n$-Dodecane (>99\% purity) and pyridine ( $>99 \%$ purity) were obtained from Fluka. $\mathrm{Ar}(>99.99 \%)$ and $5 \% \mathrm{H}_{2} / \mathrm{Ar}$ gases were supplied by AGA. All chemicals were used as received.

2.2. Catalyst Preparation and Characterization. Pd (2 wt $\%)$ on sibunit (synthetic mesoporous carbon) was prepared by the following previously published method: ${ }^{41}$ Sibunit was treated with $5 \% \mathrm{HNO}_{3}$ overnight at $25{ }^{\circ} \mathrm{C}$ and dried at $80{ }^{\circ} \mathrm{C} . \mathrm{H}_{2} \mathrm{PdCl}_{4}$ was hydrolyzed in an aqueous solution, $\mathrm{Na}_{2} \mathrm{CO}_{3}$ was added until a $\mathrm{pH} 9$ was reached, and sibunit was added to this solution for deposition of $\mathrm{Pd}$ (II) hydro complexes. The solution was left for $6 \mathrm{~h}$ at $25^{\circ} \mathrm{C}$ and then filtered and washed with $\mathrm{H}_{2} \mathrm{O}$ until no chloride ions were detected in the wash water. The catalyst was finally dried and subsequently calcined for $2 \mathrm{~h}$ at $200^{\circ} \mathrm{C}$.

The particle diameter distributions and mean Pd diameters were calculated based on the frequency of particles from images obtained with a LEO 912 OMEGA energy-filtered transmission electron microscopy (TEM) instrument operating with acceleration voltage of $120 \mathrm{kV}$. At least 100 particles were counted to obtain the average particle diameter of $\mathrm{Pd}$. The fresh and spent catalyst beads were crushed to a powder, mixed thoroughly, and glued to an epoxy plate.

The X-ray diffraction (XRD) mean particle diameter based on particle volume were calculated with the Scherrer formula from powder diffractograms obtained on a Siemens D5000 X-ray powder diffractometer

Pore volume and specific surface area measurements were conducted with a physisorption/chemisorption Sorptometer 1900 apparatus from Carlo Erba with liquid $\mathrm{N}_{2}$ at $77 \mathrm{~K}$. Specific surface areas were calculated from the $\mathrm{N}_{2}$ adsorption-desorption isotherms using the Brunauer-Emmett-Teller (BET) equation. The pore size distribution was obtained from the DollimoreHeal correlation.

The distribution of active metal in fresh catalyst beads was investigated by laser-ablation inductively coupled plasma mass spectrometry (LA-ICP-MS), with a New Wave UP-213 laser ablation system and a Perkin-Elmer ICP-MS Sciex Elan 6100 DRC Plus system. A number of catalyst beads were cut in half and fixed in epoxy glue for the measurements.

Reactor effluent contents of Pd were measured by inductively coupled plasma optical emission spectrometry (ICP-OES) with a Perkin-Elmer 5300 DV optical emission spectrometer. For each experiment, $0.2 \mathrm{~g}$ of effluent was added to $5 \mathrm{~mL}$ of $65 \% \mathrm{HNO}_{3}$ (aqueous) and $1 \mathrm{~mL}$ of $30 \% \mathrm{H}_{2} \mathrm{O}_{2}$ (aqueous), heated in a microwave oven, and then diluted to $100 \mathrm{~mL}$ (with water) before ICP-OES analysis.

2.3. Reactor Loading, Catalyst Activation, and Deoxygenation. A tubular reactor of $18-\mathrm{cm}$ height and $1.58-\mathrm{cm}$ inner diameter (volume $=35.1 \mathrm{~mL}$ ) was loaded from the bottom up with a small layer of quartz wool, followed by $6 \mathrm{~mL}$ of quartz sand of $0.2-0.8-\mathrm{mm}$ diameter and a layer of quartz wool. Afterward, 
the catalyst bed of $10 \mathrm{~g}$ (volume uptake $=19.0 \mathrm{~mL}$ ) of Pd/sibunit was loaded into the reactor. Thereafter, a layer of quartz wool, $4 \mathrm{~mL}$ of quartz sand, and another layer of quartz wool were introduced. The quartz sand and quartz wool mixed the inlet flow

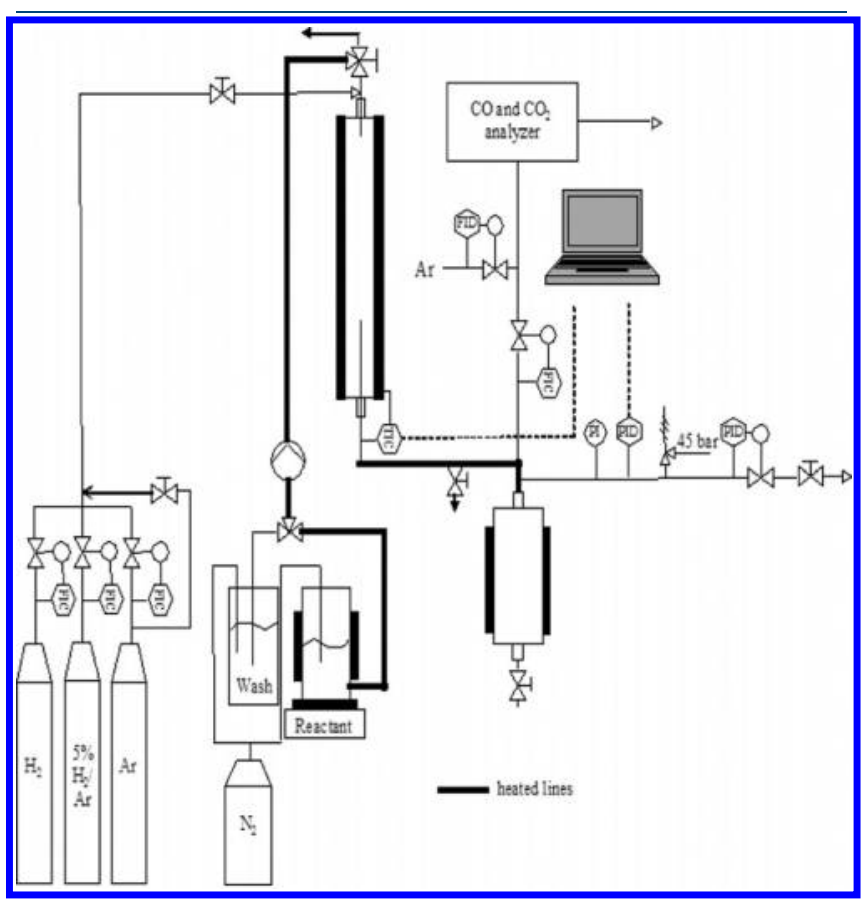

Figure 1. Flow reactor schematic for the continuous deoxygenation of stearic acid. in the reactor as well as the outlet flow to make the liquid flow behavior and sampling uniform.

A thermocouple was fixed at the center of the catalyst bed. Then, the reactor was mounted and leak-tested with $\mathrm{Ar}$ at room temperature, and afterward, it was purged for $16 \mathrm{~h}$ at 20 bar with Ar also at room temperature. An aluminum heating element was fitted around the reactor.

The catalyst was then activated in $5 \% \mathrm{H}_{2} / \mathrm{Ar}$ at 20 bar by being heated at $10^{\circ} \mathrm{C} / \mathrm{min}$ to $150{ }^{\circ} \mathrm{C}$, held at $150{ }^{\circ} \mathrm{C}$ for $1 \mathrm{~h}$, and then heated at $10{ }^{\circ} \mathrm{C} / \mathrm{min}$ to the reaction temperature of $300{ }^{\circ} \mathrm{C}$. Reactions were performed in either pure $\mathrm{Ar}$ or $5 \% \mathrm{H}_{2} / \mathrm{Ar}$ at $42 \mathrm{~N} \mathrm{~mL} / \mathrm{min}$ and with a flow of either pure stearic acid or $10 \mathrm{wt} \%$ stearic acid in $n$-dodecane, both at $0.075 \mathrm{~mL} / \mathrm{min}$.

Because stearic acid melts at $70{ }^{\circ} \mathrm{C}$, it was kept in a heated feed vessel at $90{ }^{\circ} \mathrm{C}$, and the pump and inlet piping were kept at $100^{\circ} \mathrm{C}$ during experiments with pure stearic acid. Trace gas impurities (e.g., molecular oxygen) were expelled from the feed vessel by continuous purging of $20 \mathrm{~mL} / \mathrm{min} \mathrm{N}_{2}$ gas through the stearic acid. The flow reactor setup is sketched in Figure 1. During experiments, liquid samples of ca. $0.1 \mathrm{~g}$ were withdrawn in glass vials downstream the reactor, and the remaining liquid effluent was led to a heated collector vessel to be purged at set intervals. Gases were purged continuously by a pressure reduction controller, and part of the gas stream was diluted in $\mathrm{He}$ and analyzed for $\mathrm{CO}$ and $\mathrm{CO}_{2}$ on a Siemens ULTRAMAT 6 online IR analyzer. The glass vials with liquid samples were weighed, and $4 \mathrm{~mL}$ of $n$-dodecane was added to each glass vial as a solvent. Of this, an aliquot of $10.0 \mu \mathrm{L}$ was transferred to a gas chromatography (GC) vial, followed by addition of $100 \mu \mathrm{L}$ of dodecane, $100 \mu \mathrm{L}$ of pyridine, and $50 \mu \mathrm{L}$ of BSTFA for derivatization, and the mixture was left to stand

Table 1. Step Changes during Continuous Decarboxylation with Dilute and Pure Stearic Acid over 2 wt \% Pd/Sibunit

\begin{tabular}{|c|c|c|c|}
\hline step change & TOS (min) & condition & changes applied \\
\hline \multicolumn{4}{|c|}{ Dilute Stearic Acid in $5 \% \mathrm{H}_{2} / \mathrm{Ar}$} \\
\hline & -55 & liquid & flow of dodecane started \\
\hline I & 0 & liquid & $10 \mathrm{~mol} \%$ stearic acid in dodecane \\
\hline II & 300 & gas & $5 \% \mathrm{H}_{2} / \mathrm{Ar}$ \\
\hline \multicolumn{4}{|c|}{ Dilute Stearic Acid in $5 \% \mathrm{H}_{2} / \mathrm{Ar}$} \\
\hline III & 1575 & gas & pure $\mathrm{Ar}$ \\
\hline IV & 1816 & liquid & $6.55 \mathrm{~mol} \%$ stearic acid in dodecane \\
\hline \multirow[t]{5}{*}{$\mathrm{V}$} & 3016 & liquid & dodecane \\
\hline & 4389 & temperature & quenching to $150{ }^{\circ} \mathrm{C}$ started \\
\hline & \multicolumn{3}{|c|}{$100 \%$ Stearic Acid in Ar } \\
\hline & 4359 & temperature & heating from 150 to $300{ }^{\circ} \mathrm{C}$ started \\
\hline & 4389 & & reactor heated \\
\hline VI & 4481 & liquid & $100 \%$ stearic acid \\
\hline \multirow[t]{5}{*}{ VII } & 7056 & liquid & dodecane \\
\hline & 7056 & temperature & quenching from 300 to $150{ }^{\circ} \mathrm{C}$ started \\
\hline & \multicolumn{3}{|c|}{$100 \%$ Stearic Acid in $5 \% \mathrm{H}_{2} / \mathrm{Ar}$} \\
\hline & 7056 & temperature & heating from 150 to $300{ }^{\circ} \mathrm{C}$ at $15^{\circ} \mathrm{C} / \mathrm{min}$ started \\
\hline & 7056 & gas & $5 \% \mathrm{H}_{2} / \mathrm{Ar}$ \\
\hline VIII & 7066 & liquid & $100 \%$ stearic acid \\
\hline \multirow[t]{4}{*}{ IX } & 18506 & liquid & dodecane \\
\hline & 18881 & gas & pure $\mathrm{Ar}$ \\
\hline & 18881 & liquid & flow stopped \\
\hline & 18881 & temperature & reactor cooling to $25^{\circ} \mathrm{C}$ started \\
\hline
\end{tabular}




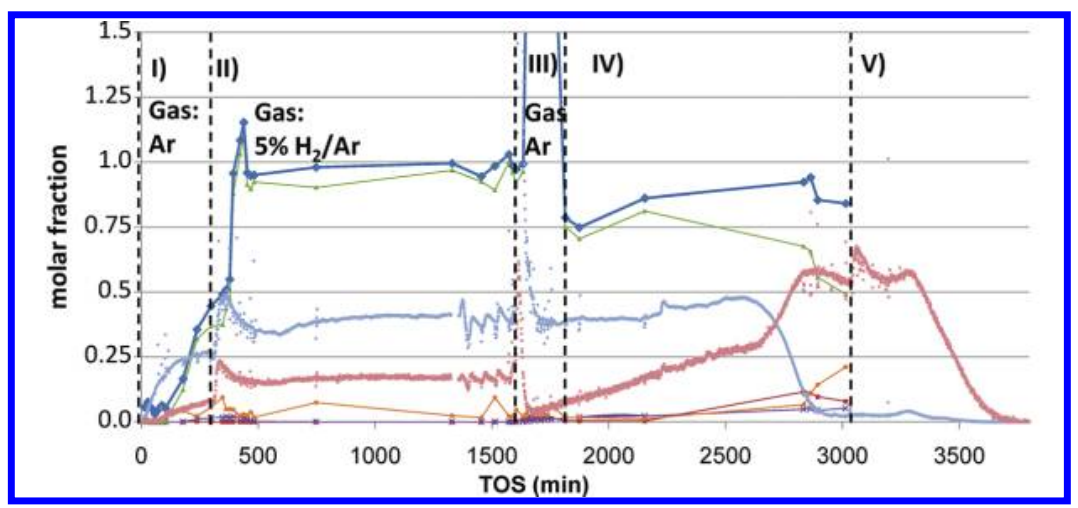

Figure 2. Decarboxylation in liquid flow of stearic acid over $\mathrm{Pd} / \mathrm{C}$ at $300{ }^{\circ} \mathrm{C}$ diluted in dodecane at $0.075 \mathrm{~mL} / \mathrm{min}, 5 \% \mathrm{H}_{2} / \mathrm{Ar}$, or pure $\mathrm{Ar}$ gas at 20 bar at $42 \mathrm{~N} \mathrm{~mL} / \mathrm{min}$. Changes in the operating parameters: (I) gas $=\mathrm{Ar}$, (II) gas $=5 \% \mathrm{H}_{2} / \mathrm{Ar}$, (III) erroneous liquid sampling, (IV) gas $=\mathrm{Ar}$, (V) liquid $=$ dodecane. Legend: Liquid mole balance (dark blue diamonds), stearic acid (orange circles), heptadecane (green triangles), heptadecene (brown squares), undecylbenzene (purple $\times$ 's), $\mathrm{CO}$ (maroon $\times$ 's), $\mathrm{CO}_{2}$ (light blue diamonds). The Roman numerals refer to Table 1 .

at $70^{\circ} \mathrm{C}$ for $60 \mathrm{~min}$. An overview of the reactor step changes is provided in Table 1.

After reaction, the reactor was washed for several hours with dodecane and Ar gas. Thereafter, the system was cooled, and the pressure was carefully reduced. The reactor was disassembled, and the spent catalyst beads were sorted into sample glasses depending on their axial position in the reactor bed.

\section{RESULTS AND DISCUSSION}

3.1. Steady-State Decarboxylation of Stearic Acid. 3.1.1. Stearic Acid Diluted in Dodecane: Step Changes II and III. At 450-1575 min time-on-stream (TOS), the reaction was performed in $5 \% \mathrm{H}_{2} /$ Ar. The reactor was kept under steady-state conditions while liquid samples were extracted. The online analysis of $\mathrm{CO}_{2}$ and $\mathrm{CO}$ concentrations showed that a conversion of around $60 \%$ would have been achieved; however, from the liquid samples, it was clear that the conversion of stearic acid to heptadecane was close to $95 \%$ at full selectivity. The discrepancy between the $\mathrm{CO} / \mathrm{CO}_{2}$ and liquid-phase analyses is likely due to the formation of methane through the methanation of $\mathrm{CO}_{2}, \mathrm{CO}$, or both because of the hydrogen content in the sweep gas. Any methane formed could not be measured on the Ultramat instrument in the present configuration.

3.1.2. Effect of Ar: Step Changes IV and V. To determine whether this behavior would persist in a hydrogen-free atmosphere, the sweep gas was changed back to Ar at TOS $=1575$ $\mathrm{min}$. The concentration in the feed vessel was also lowered from $10 \mathrm{~mol} \%$ (ca. $15 \mathrm{wt} \%$ ) to $6.5 \mathrm{~mol} \%$ (10 wt \%) stearic acid.

Initially, a steep increase in gas and liquid concentrations was seen because of an unintended blocking of the gas feed line (Figure 2, section III), which was unblocked shortly thereafter. Stable operation was approached, and correctly sampled liquid was obtained at TOS $=1816 \mathrm{~min}$ for pure Ar sweep gas. Initially, only heptadecane and $\mathrm{CO}_{2}$ were formed but no $\mathrm{CO}$. The $\mathrm{CO}_{2}$ concentration corresponded to $50 \mathrm{~mol} \%$ of the concentration of heptadecane. However, the $\mathrm{CO}$ concentration exiting the reactor increased over time, and at TOS = 2650-2850 $\mathrm{min}$, the $\mathrm{CO}_{2}$ concentration dropped to practically zero as the concentration of $\mathrm{CO}$ rose even more before settling at a concentration corresponding to around $55 \%$ conversion at $2800 \mathrm{~min}$ TOS. The liquid samples also were found to contain high levels of heptadecene ( $\mathrm{C}_{17}$ alkene) of
$8-12 \%$ and undecylbenzene $\left(\mathrm{C}_{17}\right.$-monoaromate $)$ of $4-5 \%$, as well as unconverted stearic acid (20\%). The production of heptadecane $\left(\mathrm{C}_{17}\right.$ alkane $)$ started to drop as well. The formation of unsaturated compounds is likely caused by the lack of added $\mathrm{H}_{2}$, leading to cyclization and dehydrogenation of the products.

The initial lack of $\mathrm{CO}$ might be due to the lack of $\mathrm{H}_{2}$ affording the reverse water-gas-shift (WGS) reaction; however, the constant and gradual rise in $\mathrm{CO}$ concentration followed (with a delay of $1-2 \mathrm{~h}$ ) the formation of heptadecane and liberation of $\mathrm{H}_{2}$ through aromatization to undecylbenzene. $\mathrm{H}_{2} \mathrm{O}$ and $\mathrm{H}_{2}$ might have been formed by these side reactions.

The formation of linear hydrocarbons from FFAs has been proposed to take place by a mechanism going through formic acid: First, the fatty acid splits into formic acid and 1-alkene. Then, formic acid rapidly decomposes, by either dehydrogenation to $\mathrm{CO}_{2}$ and $\mathrm{H}_{2}$ or dehydration to $\mathrm{CO}$ and $\mathrm{H}_{2} \mathrm{O}$ (overall reactions 1 and 2). Hydrogen from the gas phase later saturated the formed alkene. ${ }^{42,43}$ This can explain the enhanced formation of unsaturated compounds during reaction in pure Ar. Formic acid, however, quickly decomposed under the present conditions and therefore could not be observed in the liquid or gas phase. $^{44}$

Heptadecene and aromatic $\mathrm{C}_{17}$ compounds are formed during reaction where catalyst deactivation is often fast. ${ }^{36,38}$ Therefore, the flow was switched to dodecane at TOS $=3120 \mathrm{~min}$, and the Ar flow was maintained to wash the reactor (Figure 2, step V). The $\mathrm{CO}$ and $\mathrm{CO}_{2}$ concentrations did not start to decline until TOS $=3300 \mathrm{~min}$, when the reactor was cooled to $150{ }^{\circ} \mathrm{C}$. The sum of the molar amounts of $\mathrm{CO}$ and $\mathrm{CO}_{2}$ detected in the IR analyzer after the liquid flow was switched to dodecane corresponded to $4.21 \mathrm{mmol}$, whereas at most $0.250 \mathrm{mmol}$ of CO could be situated on the surface of the Pd particles (calculated from the $\mathrm{XRD}$ mean diameter of $12 \mathrm{~nm}$ as reported in section 3.3, taking particles as spheres and the $\mathrm{Pd} / \mathrm{CO}$ ratio as 2$).{ }^{45}$ Thus, the $\mathrm{CO}$ and $\mathrm{CO}_{2}$ measured in the dodecane liquid flow came from reactant holdup in the catalyst bed; the stearic acid situated in the pores of the catalyst particles continued to react.

3.1.3. Effect of Concentrated Stearic Acid under Ar: Step Changes VI and VII. Following the reaction with $10 \mathrm{wt} \%$ stearic acid in dodecane, the reactor was flushed overnight with Ar and cooled to ambient temperature, after which it was reheated to $150{ }^{\circ} \mathrm{C}$, flushed for several hours with dodecane and argon and 

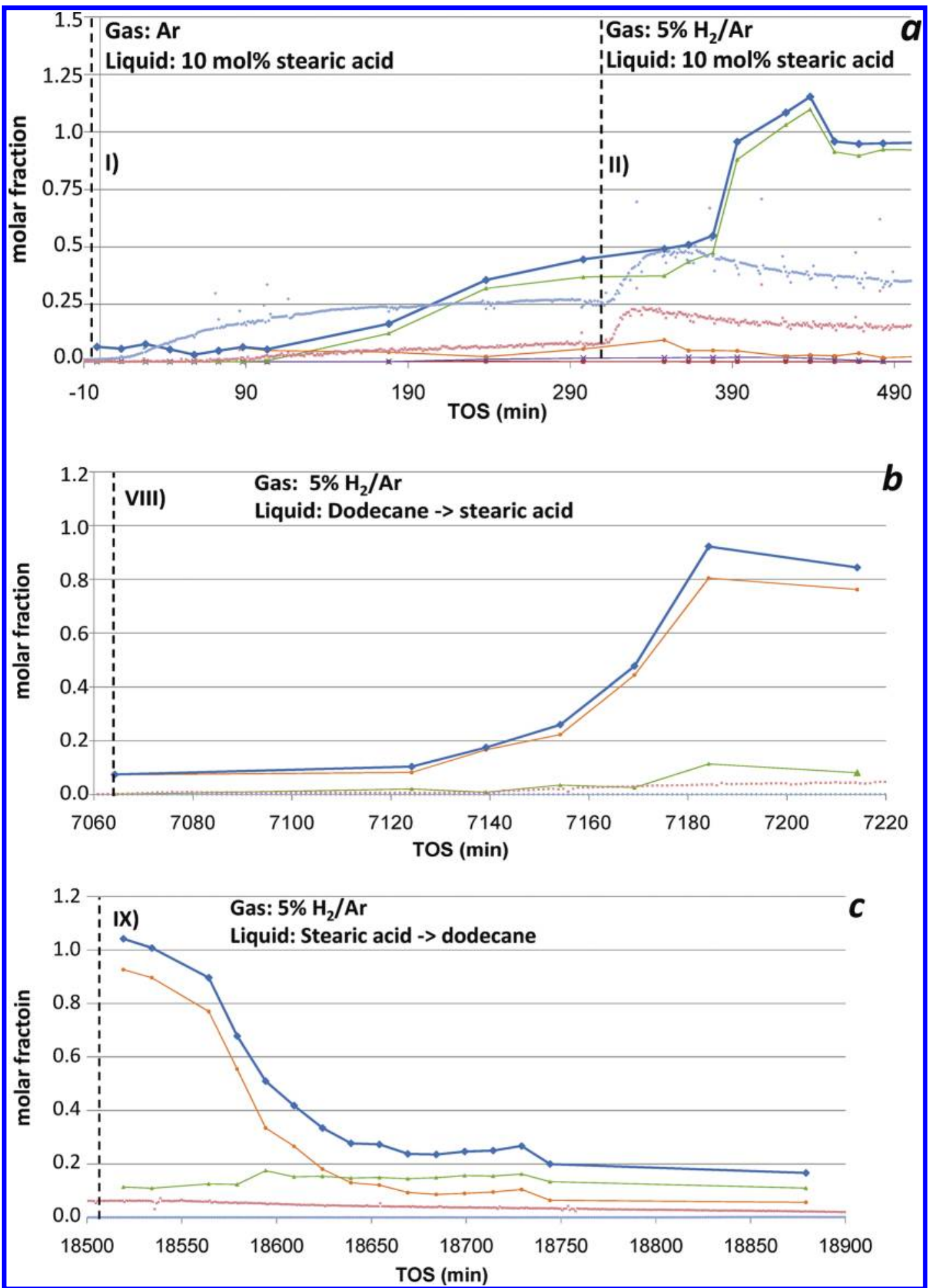

Figure 3. Mole fraction based on stearic acid, steady-state decarboxylation of $100 \%$ stearic acid flow. (a) Pure Ar gas at 20 bar from step change VI to step change VII. (b) $5 \% \mathrm{H}_{2} /$ Ar gas at 20 bar from step VIII to step IX. Legend: Liquid mole balance (dark blue diamonds), stearic acid (orange circles), heptadecane (green triangles), heptadecene (brown squares), undecylbenzene (purple $\times$ 's), $\mathrm{CO}$ (maroon $\times$ 's), $\mathrm{CO}_{2}$ (light blue + 's). The Roman numerals refer to Table 1 .

then with just argon. Then, the reactor was reheated to 300 at $10{ }^{\circ} \mathrm{C} / \mathrm{min}$, and a flow of pure stearic acid was fed to the reactor to determine the steady-state deoxygenation of concentrated stearic acid in Ar during the following time interval of 2 days (TOS $=4481-7060 \mathrm{~min}$ ). This is shown in Figure 3a.
The mass balance of liquid samples performing the deoxygenation of pure stearic acid under Ar was only ca. $80 \%$. At the same time, about $2 \%$ heptadecane was formed in the start of the period, decreasing with time to about $1 \%$ at the end. The online IR-active analysis showed CO corresponding to about $3 \%$ 
Table 2. Comparison of the Steady-State Yields of Heptadecane (mol \%) Using Different Stearic Acid Concentrations in the Feed ${ }^{a}$

\begin{tabular}{|c|c|c|}
\hline \multirow[b]{2}{*}{ liquid feed } & \multicolumn{2}{|r|}{ sweep gas atmosphere } \\
\hline & $5 \% \mathrm{H}_{2}$ in $\mathrm{Ar}$ & pure Ar \\
\hline $\begin{array}{l}\text { dilute stearic acid (mol \% stearic acid } \\
\text { in dodecane) }\end{array}$ & $95 \%(15 \mathrm{~mol} \%)$ & $\begin{array}{l}75 \% \text { decreasing to } 55 \% \text {, formation of unsaturated and } \\
\text { aromatic } \mathrm{C}_{17} \text { compounds }(10 \mathrm{~mol} \%)\end{array}$ \\
\hline pure stearic acid & $12 \%$ & $2 \%$ decreasing to $1 \%$, possible formation of heavier products \\
\hline
\end{tabular}

conversion, decreasing over time to about $1.5 \%$. No 1 -heptadecene was detected; therefore, methanation was assumed not to have taken place. It is suspected that coupling reactions with unsaturated compounds, reactants, or both might take place, for instance, coupling of formed alkenes to tetratriacontene ( $\mathrm{C}_{34}$-alkene). 18-Oxopentatriacontane $\left(\mathrm{C}_{35}\right.$-ketone) formed by ketonization is less likely to have been formed, however, as it usually requires a basic metal oxide as a support. ${ }^{33,46}$ The heavy components formed would not have vaporized easily in split/ splitless injection in GC analysis and might well have been too heavy to be seen with the applied GC method. It can be concluded that the lack of added $\mathrm{H}_{2}$ in the gas feed led to low activity and gradual deactivation of the catalyst during the ca. 2600 min TOS mentioned.

3.1.4. Effect of Concentrated Stearic Acid under $5 \% \mathrm{H}_{2} / \mathrm{Ar}$ : Step Changes VIII and IX. After the Ar experiment described in section 3.1.3, the next step was to assess the effect of $5 \% \mathrm{H}_{2} / \mathrm{Ar}$ as gas atmosphere. The reactor was again cooled to $150{ }^{\circ} \mathrm{C}$, flushed with dodecane to wash out residual stearic acid and products, and reheated to $300{ }^{\circ} \mathrm{C}$ to make a new attempt to analyze the startup transient and steady-state conversion in $5 \% \mathrm{H}_{2} / \mathrm{Ar}$ atmosphere (Figure 3b).

From 8300 to $18500 \mathrm{~min}$ TOS, the production of heptadecane was constant at around $12 \%\left(5 \% \mathrm{H}_{2} / \mathrm{Ar}\right.$ atmosphere $)$, and no other products were detected in the liquid phase. In the gas phase, only $\mathrm{CO}$ was detected, corresponding to a conversion of between $8 \%$ and $6 \%$, decreasing with time. CO might have formed from $\mathrm{CO}_{2}$ as a result of the WGS equilibrium in the $\mathrm{H}_{2}$ containing atmosphere or from deoxygenation through formic acid. ${ }^{42,43}$ The missing $\mathrm{CO}$ or $\mathrm{CO}_{2}$ was most likely converted to compounds not detectable in the IR-active online analysis, with methane being a possible product or coke through the Boudouard reaction. $\mathrm{CO}_{2}$ formed from the Boudouard reaction could again react with $\mathrm{H}_{2}$ to $\mathrm{CO}$ by WGS or with more $\mathrm{H}_{2}$ to form methane.

3.1.5. Comparison of the Catalyst Performance for Different Gas and Liquid Feeds. The steady-state deoxygenation experiments with stearic acid are compared in Table 2. It is evident that the lack of $\mathrm{H}_{2}$ in the feed led to deactivation, whereas stable catalyst activity was upheld in $5 \% \mathrm{H}_{2} / \mathrm{Ar}$. Initial deactivation during the deoxygenation of neat stearic acid was previously observed using 20 bar $\mathrm{Ar}$ instead of $5 \% \mathrm{H}_{2} / \mathrm{Ar}$ as the sweep gas over $5 \% \mathrm{Pd} /$ sibunit at $360{ }^{\circ} \mathrm{C}$, but it was not found that the initial catalyst activity could be regained at this temperature: a stable conversion of about $15 \%$ neat stearic acid was obtained under $5 \%$ $\mathrm{H}_{2} / \mathrm{Ar}$ at $360{ }^{\circ} \mathrm{C},{ }^{35}$ comparable with the $12 \%$ conversion of neat stearic acid in $5 \% \mathrm{H}_{2} / \mathrm{Ar}$ at $300{ }^{\circ} \mathrm{C}$ obtained in the present study.

3.2. Transients during Step Changes. Three transients in the catalytic deoxygenation over $\mathrm{Pd} /$ sibunit are emphasized here, namely, the flow pattern during startup for $10 \%$ stearic acid in $n$-dodecane and the startup and shutdown of $100 \%$ stearic acid

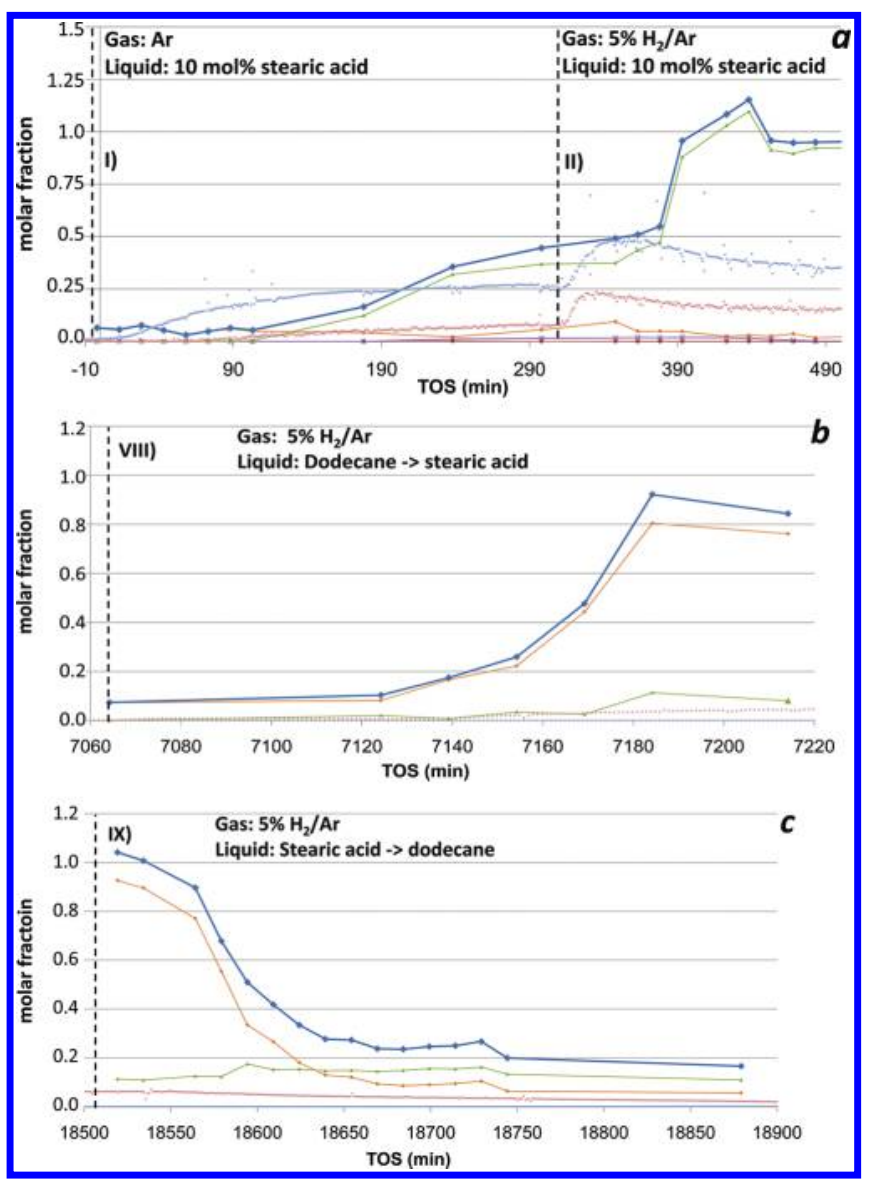

Figure 4. Mole balances based on stearic acid feed content for step changes. (a) Startup of $10 \mathrm{~mol} \%$ stearic acid in dodecane flow: step changes I and II. (b) Startup of 100\% stearic acid flow: step change VIII. (c) Shutdown of $100 \%$ stearic acid flow: step change IX. Legend: Liquid mole balance (dark blue diamonds), stearic acid (orange circles), heptadecane (green triangles), heptadecene (brown squares), undecylbenzene (purple $\times$ 's), $\mathrm{CO}$ (marroon $\times$ 's), $\mathrm{CO}_{2}$ (light blue + 's). The Roman numerals refer to Table 1 .

under $5 \% \mathrm{H}_{2} /$ Ar. The liquid pumping speeds were the same for the three conditions. The transients can be seen in Figure $4 a-c$.

There was a considerable holdup time when the flow was switched to or from dodecane until the sample on the outlet side of the reactor was affected: approximately $1 \mathrm{~h}$ in all experiments, as seen in Figure $4 a-c$. Once the concentration in the liquid samples had started to change, the transient lasted another 1.5-2 $\mathrm{h}$ before the steady-state concentration was reached and the reactor stabilized. During shutdown, the concentration of reactant and products did not fall to zero, as an additional number of hours were needed to completely remove the last compounds 
probably located in the porous catalyst beads and in cavities connected to the reactor.

3.2.1. Startup of Stearic Acid Diluted in Dodecane: Step Changes I and II. After initial leak testing of the reactor, the liquid flow was switched to Ar flushing overnight, and the catalyst was reduced in 20 bar of $5 \% \mathrm{H}_{2} /$ Ar: First, the reactor was heated at $10^{\circ} \mathrm{C} / \mathrm{min}$ to $150^{\circ} \mathrm{C}$, where it was kept for $1 \mathrm{~h}$, after which it was heated at $10{ }^{\circ} \mathrm{C} / \mathrm{min}$ to the reaction temperature of $300{ }^{\circ} \mathrm{C}$. Then, the flow was switched to pure Ar, and the pumping of $10 \mathrm{~mol} \%$ stearic acid in dodecane was started (at TOS $=0 \mathrm{~min}$ ), as depicted in Figure 4a.

After about $15 \mathrm{~min}$, the $\mathrm{CO}_{2}$ concentration from the online $\mathrm{CO}_{2} / \mathrm{CO}$ analysis started to rise, meaning that decarboxylation of the reactant was taking place. However, the first traces of heptadecane in the liquid phase only occurred more than $2 \mathrm{~h}$ after the step change. The productions of $\mathrm{CO}_{2}$ and $\mathrm{CO}$ as well as heptadecane seemed to be stable at TOS $=300 \mathrm{~min}$, with both gas and liquid phase corresponding to $35-40 \%$ conversion.

Thereafter, the gas atmosphere was changed to $5 \% \mathrm{H}_{2} / \mathrm{Ar}$ at TOS $=300 \mathrm{~min}$, and the liquid flow was kept constant. The $\mathrm{CO}_{2}$ and $\mathrm{CO}$ concentrations as determined by the online $\mathrm{CO} / \mathrm{CO}_{2}$ analysis start to respond to this change after about $15 \mathrm{~min}$; however, the corresponding response in heptadecane concentration was not visible in the liquid-phase analysis before $1 \mathrm{~h}$ (around TOS $=360 \mathrm{~min}$ ), and a steady state was reached only $2.5 \mathrm{~h}$ after the step change was induced (around TOS $=450 \mathrm{~min}$ ). At TOS $=475 \mathrm{~min}$, the steady-state concentration profile had developed, and the mass balance was compute as $90-95 \%$ heptadecane compared to theoretically possible value, as well as $5 \%$ stearic acid.

It is suspected that the liquid feed built up a trickling film wetting the beads of the catalyst bed and quartz material and that the slow response in stearic acid concentration was due to the low overall flow of the reactant. The solvent $n$-dodecane has a normal boiling point of $216^{\circ} \mathrm{C}$ (its vapor pressure is 6 bar at $300^{\circ} \mathrm{C}$ ), and the products heptadecane and 1-heptadecene have normal boiling points of ca. $302{ }^{\circ} \mathrm{C}$ (vapor pressures around 1 bar at $300^{\circ} \mathrm{C}$ ); as these compounds are not supplied or produced in amounts sufficient to saturate the gas phase, they will vaporize and quickly leave the reactor with the sweep gas once formed. Stearic acid is not suspected to have vaporized (its boiling point is $383^{\circ} \mathrm{C}$ ) and will have propagated through the reactor in liquid form. The low feed rate of stearic acid means that a trickling liquid film hereof will propagate through the reactor very slowly.

3.2.2. Startup of $100 \%$ Stearic Acid Feed in $5 \% \mathrm{H}_{2} /$ Ar: Step Change VIII. Following reaction with liquid feed of $100 \%$ stearic acid under pure Ar atmosphere, the reactor was flushed for several hours with liquid dodecane followed by $\mathrm{Ar}$ gas at $150^{\circ} \mathrm{C}$. Finally, the gas atmosphere was switched to $5 \% \mathrm{H}_{2} / \mathrm{Ar}$, and flow of stearic acid to the reactor was started at TOS = $7060 \mathrm{~min}$. The CO signal increased slightly after $5 \mathrm{~min}$ (no $\mathrm{CO}_{2}$ formation was observed), but an increase in the concentration of stearic acid was not seen before $60-75 \mathrm{~min}$. The concentrations of stearic acid and product heptadecane rose over an additional 1-h period before approaching steady-state values with up to $12 \%$ conversion (TOS $=7190 \mathrm{~min}$ ). This is depicted in Figure $4 \mathrm{~b}$.

3.2.3. Shutdown of $100 \%$ Stearic Acid Feed in $5 \% \mathrm{H}_{2} /$ Ar: Step Change IX. After more than $10000 \mathrm{~min}$ on stream in stable behavior, the flow was switched from pure stearic acid to pure dodecane to initiate reactor shutdown (at TOS $=18500 \mathrm{~min}$ ); see Figure 4c. The CO signal from the online analysis was affected after a few minutes and started to decline gradually over a period of $8 \mathrm{~h}$. In the liquid sampling, the response to this step change was seen after ca. $1 \mathrm{~h}$, and the concentration of stearic acid declined to $10 \%$ at $2.5 \mathrm{~h}$ after the step change. Peculiarly, the concentration of heptadecane did not decrease within 3-4 h after the step change. After these few hours, the concentrations decreased only very slowly. This behavior is ascribed to the presence of small reservoirs of liquid after the reactor, specifically, in the thermocouple fittings or quartz material after the catalyst bed. This also means that the apparatus might not be completely liberated of stearic acid despite the purging with dodecane at 300 or $150{ }^{\circ} \mathrm{C}$ through the reactor for several hours prior to switching to stearic acid flow. Therefore, minute amounts of stearic acid might appear in the samples already before the flow of stearic acid is introduced in the reactor. It is presumed that both stearic acid and products were still situated in the microporous catalysts beads, because of capillary forces, a long time after the liquid flow was stopped and, from here, they only slowly mixed into the reactor after the switch to dodecane. This could explain the constant production of heptadecane despite the abrupt decrease in stearic acid concentration.

3.3. Postreaction Analyses: Catalyst Deactivation. A thorough postreaction analysis of the spent catalyst was performed. The reactor was flushed first in $n$-dodecane and then flushed extensively in Ar gas at $150{ }^{\circ} \mathrm{C}$. The reactor was then dismantled and the catalyst taken out of the reactor in a stepwise manner by sorting the catalyst beads into batches depending on their axial position in the bed.

The total weight of the dried catalyst bed extracted from the reactor summed to $12.72 \mathrm{~g}$ versus fresh weight of $10 \mathrm{~g}$, thus the uptake of carbonaceous species is $2.72 \mathrm{~g}$ or $0.227 \mathrm{~mol}$ of C. In comparison, the total molar amount of stearic acid passing through the reactor is $3.43 \mathrm{~mol}$ stearic acid or $61.7 \mathrm{~mol}$ of C, giving a ratio of coke-to-stearic acid percentage of $6.6 \%$. The white and transparent quartz wool and quartz sand near the reactor inlet and the outlet were not colored by the process. This indicates that coking can be attributed to the catalyst itself.

LA-ICP-MS confirmed that palladium is impregnated in an "eggshell-like" layer in the outer rim of the carbon beads, while the center of the particle is inert, thus minimizing the diffusion pathway. It is not expected that the majority of the palladium particles were mobile under the conditions used.

3.3.1. Coking in the Pore System. The results from the analysis of the fresh and spent catalyst beads, sorted by position in the catalyst bed are shown in Table 3 . The BET area and pore volume decreased downward in the bed, and a deactivation profile formed downward in the catalyst bed in a way that the largest amount of coke was formed in the catalyst beads near the reactor feed inlet and it decreased down the catalyst bed. Furthermore it is evident that the catalyst beads near the reactor inlet have a lower percentage of pores in the $5-10 \mathrm{~nm}$ range and below $2 \mathrm{~nm}$ compared to the beads near the reactor outlet, apparently due to a higher percentage of pores in the $2-5 \mathrm{~nm}$ range.

The coking profile suggests that the larger pores have became narrower due to the gradual coking taking place, and that some of the smaller pores have been occluded partially or completely. The byproduct formed in the pores do not completely prevent deoxygenation reaction, because a stable conversion of $12 \%$ was obtained constantly in the final $10500 \mathrm{~min}$ TOS with neat stearic acid under $5 \% \mathrm{H}_{2} /$ Ar. Further exploration of this catalyst deactivation profile as a function of bed length could be a topic 
Table 3. Characterization of the Spent Catalyst Depending on Position in the Catalyst Bed

\begin{tabular}{lcccccccccc} 
& & & \multicolumn{5}{c}{ pore size distribution based on } \\
pore diameter in nm
\end{tabular}

${ }^{a}$ Flow direction: $\downarrow .{ }^{b}$ XRD in parentheses. ${ }^{c}$ XRD mean Pd particle based on volume calculated from the Scherrer formula; TEM based on the frequency of particles counted in the micrographs. ${ }^{d}$ Based on ref 35.

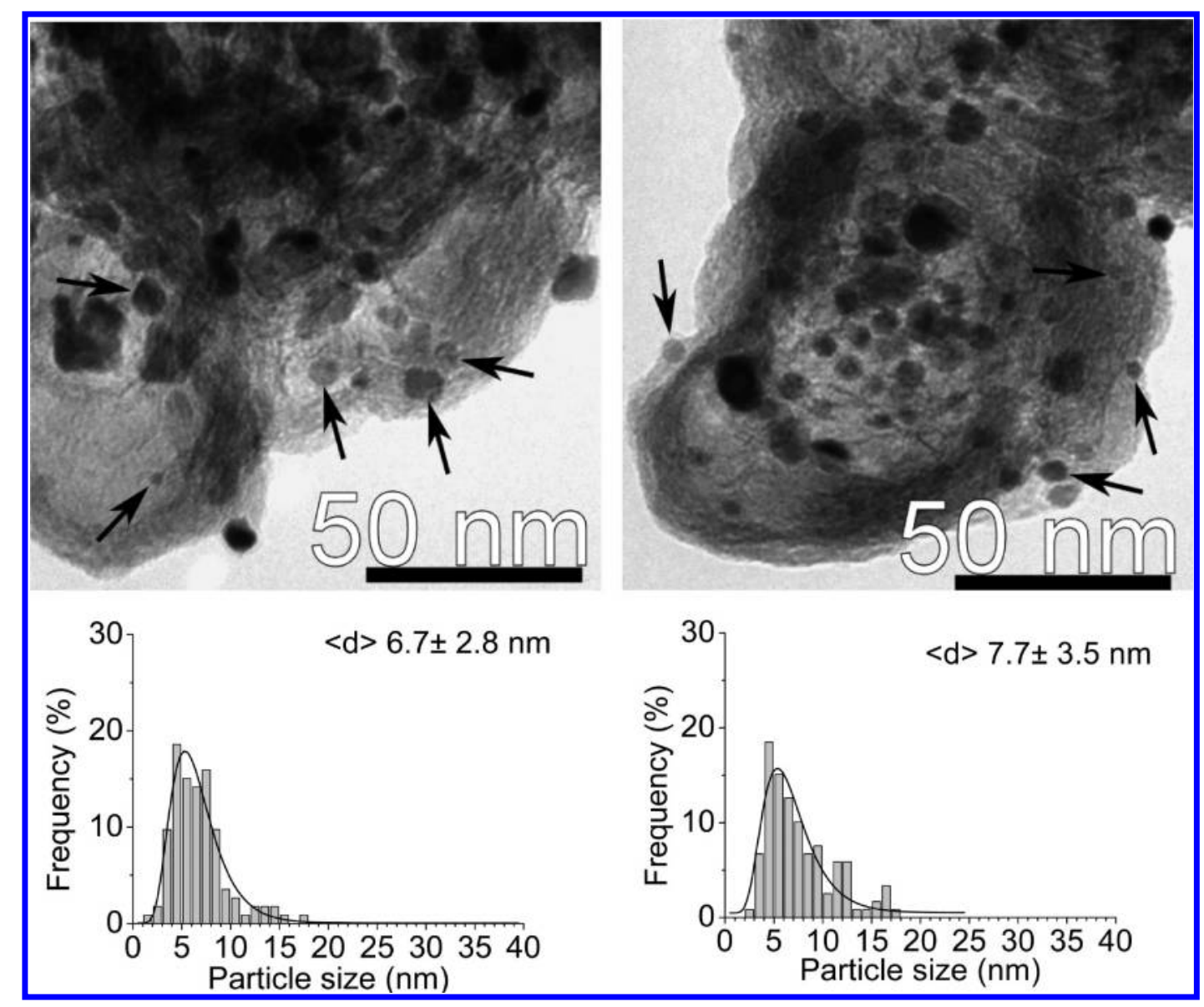

Figure 5. TEM micrographs and particle diameter distributions of (left) a fresh catalyst bead and (right) a spent catalyst bead from the top of the bed (catalyst sample 1).

of a subsequent study. It has been reported that deactivation takes place by cyclization of unsaturated compounds in hydrogen-deficient atmosphere over 1 wt \% Pd/Sibunit. ${ }^{37,38,47}$ Thus it can be concluded that catalyst deactivation is caused by coking, because the specific BET surface area decreased by $72 \%$ to $54 \%$ as a function of catalyst bed length 1 and $9 \mathrm{~cm}$ from the inlet, respectively. This has also been the case in previous studies. ${ }^{35,40}$
3.3.2. Palladium Particle Sizes. The fresh catalyst beads as well as catalyst samples 1,4 , and 6 in Table 3 were selected for transmission electron microscopy (TEM) and XRD analysis to obtain average particle sizes of the palladium and particle size distributions. The results are shown in Table 3, and a highresolution TEM images and calculated particle diameter distribution of the fresh catalyst and sample 1 are shown in Figure 5. 
The differences observed between XRD and TEM mean Pd particle sizes in Table 3 are due to the different way of counting particles - XRD mean particle diameter is based on volume of the particles while TEM mean particle diameter is based on the number of particles in a small area. According to Figure 5, there is a percentage of particles above $10 \mathrm{~nm}$ diameter which will contribute much more to the average particle size based on volume (XRD) in contrast to the average Pd diameter based on the frequency of counted particles (TEM). The TEM micrographs indicated an average diameter of palladium on the spent catalyst was $7.7 \mathrm{~nm}$ near the inlet, whereas it was $6.1 \mathrm{~nm}$ near the outlet of the reactor. Furthermore, the average Pd particle size in the fresh catalyst was $6.7 \mathrm{~nm}$. As TEM only analyses a tiny part of the catalyst bead, these differences are within experimental uncertainty. The mean particle diameters obtained via analysis of scattered X-rays were within a narrower interval around $12 \mathrm{~nm}$. It can be therefore concluded that deactivation is not caused by sintering. This is furthermore in accordance with previous reports on fresh and spent Pd/Sibunit catalysts for decarboxylation, both of $1 \mathrm{wt} \%$ or $5 \mathrm{wt} \% \mathrm{Pd}$ loading. Spent catalysts reported in the literature have active metal dispersions and particle sizes either marginally bigger or of the same sizes as the fresh catalysts. ${ }^{35,37,40,47}$

3.3.3. Leaching. The effluent from the reactor was collected in two batches of about $0.5 \mathrm{~kg}$ each and analyzed by ICP-OES. The total mass of $\mathrm{Pd}$ in the effluent was $1.15 \mathrm{mg}$, indicating that $0.58 \%$ of the $\mathrm{Pd}$ present in the catalyst bed $(200 \mathrm{mg})$ had leached into the effluent during the course of the entire time-on-stream period over 14 days at $300{ }^{\circ} \mathrm{C}$. The leaching in the latter 7 days was only about one-third of the leaching in the first 7 days of reaction ( $0.15 \%$ versus $0.43 \%)$. It is therefore expected that the leaching was due to a few loosely bound palladium particles on the catalyst surface and that leaching ceased with time as these particles were removed. Deactivation is, therefore, not due to leaching, which is in accordance with results the from previous studies concluding that no or less than $1 \%$ leaching of palladium takes place during deoxygenation over 1 wt $\% \mathrm{Pd} /$ sibunit. $^{37,40}$

\section{CONCLUSIONS}

The transient and steady-state behaviors of continuous stearic acid decarboxylation was studied over 2 wt \% Pd/sibunit carbon at $300{ }^{\circ} \mathrm{C}$ and 20 bar. Pure $\mathrm{Ar}$ and $5 \% \mathrm{H}_{2}$ in Ar were used as sweep gases, and both pure and dodecane-diluted feeds of stearic acid were employed as reactants.

Dilute stearic acid was almost fully converted to heptadecane in hydrogen-containing gas, whereas deactivation through the formation of unsaturated compounds took place in pure argon gas. Deactivation irreversibly changed the catalyst to produce $\mathrm{CO}$ instead of $\mathrm{CO}_{2}$. Pure stearic acid selectively yielded around $12 \%$ heptadecane in hydrogen-containing gas, whereas only $2 \%$ heptadecane and likely formation of heavier compounds resulted in hydrogen-free atmosphere.

The same catalyst was used during all of the experiments. A deactivation gradient formed during reaction as a function of the distance from the liquid feed inlet: the most deactivated catalyst beads were those closest to the inlet. Deactivation took place mainly through coke formation in the pores and on the surface, but not by agglomeration, leaching, or sintering.

\section{AUTHOR INFORMATION}

\section{Corresponding Author}

*E-mail: dmurzin@abo.fi.

\section{ACKNOWLEDGMENT}

A.T.M. acknowledges support from the Danish Research and Innovation Agency through the consortium "Waste-2-Value" and is furthermore grateful to the Laboratory of Industrial Chemistry and Reaction Engineering at Åbo Akademi University for hosting his stay in the group during 2010. The authors thank Paul Ek from the Process Chemistry Centre, Åbo Akademi University, for performing ICP-MS and ICP-OES measurements.

\section{REFERENCES}

(1) Directive 2009/28/EC of the European Parliament and of the Council of 23 April 2009 on the promotion of the use of energy from renewable sources and amending and subsequently repealing Directives 2001/77/EC and 2003/30/EC. Off. J. Eur. Union 2009, 140, 1.

(2) World Energy Outlook; International Energy Agency: Paris, France, 2010; p 700.

(3) Knothe, G.; Van Gerpen, J.; Krahl, J. The Biodiesel Handbook, 1st ed.; Knothe, G.; Van Gerpen, J.; Krahl, J., Eds.; AOCS Press: Urbana, IL, 2005.

(4) Mittelbach, M.; Remschmidt, C. Biodiesel: The Comprehensive Handbook, 3rd ed.; Mittelbach, M., Ed.; Martin Mittelbach: Graz, Austria, 2006.

(5) Kalnes, T. N.; Koers, K. P.; Marker, T.; Shonnard, D. R. A Technoeconomic and Environmental Life Cycle Comparison of Green Diesel to Biodiesel and Syndiesel. Environ. Prog. Sustainable Enerov 2009, 28, 111.

(6) Koskinen, M.; Sourander, M.; Nurminen, M. Apply a Compre-

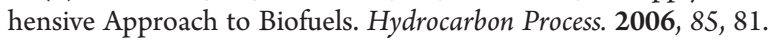

(7) Mikkonen, S. Second-Generation Renewable Diesel Offers Advantages. $H y d$ rocarbon Process. 2008, 87, 63.

(8) Sang, O. Y. Biofuel Production from Catalytic Cracking of Palm Oil. Energy Sources 2003, 25, 859.

(9) Twaiq, F. A.; Zabidi, N. A. M.; Mohameda, A. R; Bhatia, S. Catalytic Conversion of Palm Oil over Mesoporous Aluminosilicate MCM-41 for the Production of Liquid Hydrocarbon Fuels. Fuel Process. Technol. 2003, 84, 105.

(10) Lima, D. G.; Soares, V. C. D.; Riberio, E. B.; Carvalho, D. A.; Cardoso, É. C. V.; Rassi, F. C.; Mundim, K. C.; Rubim, J. C.; Suarez, P. A. Z. Diesel-Like Fuel Obtained by Pyrolysis of Vegetable Oils. I. Anal. Appl. Pyrol. 2004, 71, 987.

(11) Tamunaidu, P.; Bhatia, S. Catalytic Cracking of Palm Oil for the Production of Biofuels: Optimization Studies. Bioresour. Technol. 2007, 98, 3593.

(12) Na, J.-G.; Yi, B. E.; Kim, J. N.; Yi, K. B.; Park, S.-Y.; Park, J.-H.; Kim, J.-N.; Ko, C. H. Hydrocarbon Production from Decarboxylation of Fatty Acid without Hydrogen. Catal. Todav 2009, 156, 44.

(13) Quirino, R. L.; Tavares, A. P.; Peres, A. C.; Rubim, J. C.; Suarez, P. A. Z. Studying the Influence of Alumina Catalysts Doped with Tin and Zinc Oxides in the Soybean Oil Pyrolysis Reaction. I. Am. Oil Chem. Soc. 2008, 86, 167.

(14) Sooknoi, T.; Danuthai, T.; Lobban, L. L.; Mallinson, R.; Resasco, D. E. Deoxygenation of Methylesters over CsNaX. I. Catal. 2008, 258, 199.

(15) Danuthai, T.; Jongpatiwut, S.; Rirksomboon, T.; Osuwan, S.; Resasco, D. E. Conversion of Methylesters to Hydrocarbons over an H-ZSM5 Zeolite Catalyst. Appl. Catal. A 2009, 361, 99.

(16) Senol, O. I.; Viljava, T.-R.; Krause, A. O. I. Effect of Sulphiding Agents on the Hydrodeoxygenation of Aliphatic Esters on Sulphided Catalysts. Appl. Catal. A 2007, 326, 236.

(17) Ryymin, E.-M.; Honkela, M. L.; Viljava, T.-R.; Krause, A. O. I. Insight to Sulfur Species in the Hydrodeoxygenation of Aliphatic Esters over Sulfided NiMo $/ \gamma-\mathrm{Al}_{2} \mathrm{O}_{3}$ Catalyst. Appl. Catal. A 2009, 358, 42.

(18) Šimáček, P.; Kubička, D.; Šebor, G.; Pospísil, M. Hydroprocessed Rapeseed Oil as a Source of Hydrocarbon-Based Biodiesel. Fuel 2009, 88, 456.

(19) Šimáček, P.; Kubička, D.; Šebor, G.; Pospísili, M. Fuel Properties of Hydroprocessed Rapeseed Oil. Fuel 2010, 89, 611. 
(20) Kubička, D.; Kaluža, L. Deoxygenation of Vegetable Oils over Sulfided Ni, Mo and NiMo Catalysts. Appl. Catal. A 2010, 372, 199.

(21) Šimáček, P.; Kubička, D. Hydrocracking of Petroleum Vacuum Distillate Containing Rapeseed Oil: Evaluation of Diesel Fuel. Fuel 2010, 89, 1508.

(22) Kubička, D.; Šimáček, P.; Žilková, N. Transformation of Vegetable Oils into Hydrocarbons over Mesoporous-Alumina-Supported CoMo Catalysts. Top. Catal. 2009, 52, 161.

(23) Kubička, D.; Bejblová, M.; Vlk, J. Conversion of Vegetable Oils into Hydrocarbons over CoMo/MCM-41 Catalysts. Top. Catal. 2010, 53, 168.

(24) Huber, G. W.; O'Connor, P.; Corma, A. Processing Biomass in Conventional Oil Refineries: Production of High Quality Diesel by Hydrotreating Vegetable Oils in Heavy Vacuum Oil Mixtures. Appl. Catal. A 2007, 329, 120.

(25) Guzman, A.; Torres, J. E.; Prada, L. P.; Nuñez, M. L. Hydroprocessing of Crude Palm Oil at Pilot Plant Scale. Catal. Todav 2010, 156, 38.

(26) Morgan, T.; Grubb, D.; Santillan-Jimenez, E.; Crocker, M. Conversion of Triglycerides to Hydrocarbons over Supported Metal Catalysts. Top. Catal. 2010, 53, 820.

(27) Kubičková, I.; Snåre, M.; Eränen, K.; Mäki-Arvela, P.; Murzin, D. Yu. Hydrocarbons for Diesel Fuel via Decarboxylation of Vegetable Oils. Catal. Todav 2005, 106, 197.

(28) Hancsók, J.; Krár, M.; Magyar, S.; Boda, L.; Holló, A.; Kalló, D. Investigation of the Production of High Cetane Number Bio Gas Oil from Pre-Hydrogenated Vegetable Oils over Pt/HZSM-22/ $\mathrm{Al}_{2} \mathrm{O}_{3}$. Microporous Mesoporous Mater. 2007, 101, 148.

(29) Kikhtyanin, O. V.; Rubanov, A. E.; Ayupov, A. B.; Echevsky, G. V. Hydroconversion of Sunflower Oil on Pd/SAPO-31 Catalyst. Fuel 2010, 89, 3085.

(30) Ping, E. W.; Wallace, R.; Pierson, J.; Fuller, T. F.; Jones, C. W. Highly Dispersed Palladium Nanoparticles on Ultra-Porous Silica Mesocellular Foam for the Catalytic Decarboxylation of Stearic Acid. Microporous Mesoporous Mater. 2010, 132, 174.

(31) Do, P. T.; Chiappero, M.; Lobban, L. L.; Resasco, D. E. Catalytic Deoxygenation of Methyl-Octanoate and Methyl-Stearate on $\mathrm{Pt} / \mathrm{Al}_{2} \mathrm{O}_{3}$. Catal. Lett. 2009, 130, 9.

(32) Snåre, M.; Kubičková, I.; Mäki-Arvela, P.; Eränen, K.; Wärnå, J.; Murzin, D. Yu. Production of Diesel Fuel from Renewable Feeds: Kinetics of Ethyl Stearate Decarboxylation. Chem. Eng. I. 2007, 134, 29.

(33) Snåre, M.; Kubičková, I.; Mäki-Arvela, P.; Eränen, K.; Murzin, D. Yu. Heterogeneous Catalytic Deoxygenation of Stearic Acid for Production of Biodiesel. Ind. Eng. Chem. Res. 2006, 45, 5708.

(34) Lestari, S.; Simakova, I.; Tokarev, A.; Mäki-Arvela, P.; Eränen, K.; Murzin, D. Yu. Synthesis of Biodiesel via Deoxygenation of Stearic Acid over Supported Pd/C Catalyst. Catal. Lett. 2008, 122, 247.

(35) Lestari, S.; Mäki-Arvela, P.; Bernas, H.; Simakova, O.; Sjöholm, R.; Beltramini, J.; Lu, G. Q. M.; Myllyoja, J.; Simakova, I.; Murzin, D. Yu. Catalytic Deoxygenation of Stearic Acid in a Continuous Reactor over a Mesoporous Carbon-Supported Pd Catalyst. Energy Fuels 2009, 23, 3842.

(36) Lestari, S.; Mäki-Arvela, P.; Eränen, K.; Beltramini, J.; Max, Lu, G. Q.; Murzin, D. Yu. Diesel-Like Hydrocarbons from Catalytic Deoxygenation of Stearic Acid over Supported Pd Nanoparticles on

SBA-15 Catalysts. Catal. Lett. 2009, 134, 250.

(37) Simakova, I.; Simakova, O.; Mäki-Arvela, P.; Murzin, D. Yu. Decarboxylation of Fatty Acids over Pd Supported on Mesoporous Carbon. Catal. Todav 2010, 150, 28.

(38) Rozmysłowicz, B.; Mäki-Arvela, P.; Lestari, S.; Simakova, O. A.; Eränen, K.; Simakova, I.; Murzin, D. Yu.; Salmi, T. Catalytic Deoxygenation of Tall Oil Fatty Acids over a Palladium-Mesoporous Carbon Catalyst: A New Source of Biofuels. Top. Catal. 2010, 53, 1274.

(39) Mäki-Arvela, P.; Kubičková, I.; Snåre, M.; Eränen, K.; Murzin, D. Yu. Catalytic Deoxygenation of Fatty Acids and Their Derivatives. Energy Fuels 2007, 21, 30.

(40) Bernas, H.; Eränen, K.; Simakova, I.; Leino, A.-R.; Kordás, K.; Myllyoja, J.; Mäki-Arvela, P.; Salmi, T.; Murzin, D. Yu. Deoxygenation of Dodecanoic Acid under Inert Atmosphere. Fuel 2010, 89, 2033.
(41) Simonov, P. A.; Troitskii, S. Y.; Likholobov, V. A. Preparation of the Pd/C Catalysts: A Molecular-Level Study of Active Site Formation. Kinet. Catal. 2000, 41, 255.

(42) Berenblyum, A S.; Danyushevsky, V. Ya.; Katsman, E. A; Podoplelovau, T. A; Flid, V. R. Production of Engine Fuels from Inedible Vegetable Oils and Fats. Pet. Chem. 2010, 50, 305.

(43) Boda, L.; Onyestyák, G.; Solt, H.; Lónyi, F.; Valyon, J.; Thernesz, A. Catalytic Hydroconversion of Tricaprylin and Caprylic Acid as Model Reaction for Biofuel Production from Triglycerides. Appl. Catal. A 2010, 374, 158.

(44) Bulushev, D. A.; Beloshapkin, S.; Ross, J. R. H. Hydrogen from Formic Acid Decomposition over Pd and Au Catalysts. Catal. Todav 2010, 154, 7.

(45) Dulaurent, O.; Chandes, K.; Bouly, C.; Bianchi, D. Heat of Adsorption of Carbon Monoxide on a $\mathrm{Pd} / \mathrm{Al}_{2} \mathrm{O}_{3}$ Solid Using Infrared Spectroscopy at High Temperatures. I. Catal. 1999, 188, 237.

(46) Gärtner, C. A.; Serrano-Ruiz, J. C.; Braden, D. J.; Dumesic, J. A. Catalytic Coupling of Carboxylic Acids by Ketonization as a Processing Step in Biomass Conversion. I. Catal. 2009, 266, 71.

(47) Immer, J. G.; Lamb, H. H. Fed-Batch Catalytic Deoxygenation of Free Fatty Acids. Energy Fuels 2010, 24, 5291. 